\title{
EXPLORING THE INFLUENCE OF THE LEVEL OF TECHNOLOGY AND EXPECTED FUNCTIONS IN PRODUCT SEMANTIC
}

\author{
Kim, SoJeong (1); Yoon, JungKyoon (2); Kim, Chajoong (1) \\ 1: Department of Creative Design Engineering, Ulsan National Institute of Science and Technology \\ (UNIST); 2: Department of Design and Environmental Analysis, Cornell University
}

\begin{abstract}
This study attempted to explore how pragmatic and hedonic values are influenced by the level of technology and what particular functions have to be considered in the context of smart technologydriven design in terms of Pragmatic Value (PV) and Hedonic Value (HV). An on-line questionnaire survey was developed to answer the research questions. A total of 104 respondents participated in the survey. As target product for the study, analog watch and smart watch were selected as representative of low and high technology respectively. Semantic Differentials on PV and HV were used and expected functions were investigated via an open question. The results indicate that there are some differences between analog and smart watches in terms of PV and HV. Regarding expected functions, significant differences were identified in the study. The findings from the study could provide a better understanding of the relationship between PV and HV in terms of level of technology. If it is considered in product development process, it may contribute to an increase of user satisfaction with smarttechnology based product and service.
\end{abstract}

Keywords: Case study, Semantic data processing, Technology

\section{Contact:}

Kim, SoJeong

UNIST

$\mathrm{CDE}$

Korea, Republic of (South Korea)

gimso18@unist.ac.kr

Cite this article: Kim, S.J., Yoon, J.K., Kim, C. (2019) 'Exploring the Influence of the Level of Technology and Expected Functions in Product Semantic', in Proceedings of the 22nd International Conference on Engineering Design (ICED19), Delft, The Netherlands, 5-8 August 2019. DOI:10.1017/dsi.2019.395 


\section{BACKGROUND}

In new product development process, design practitioners try to find an ideal combination of product ${ }^{1}$ attributes such as appearance, functionality, usability, and meaningful experience based upon a understanding of user and context (Hassenzahl, 2018; Candi, 2007; Norman, 2004). At the same time, product semantic in terms of user expectation is also considered.

Considering consumers purchase goods and services and use them for two basic reasons: hedonic gratification and instrumental reasons, product semantic can be explained with hedonic and pragmatic values. Pragmatic value (hereinafter ' $P V$ ') refers to the functional, instrumental, and practical benefits, whereas hedonic value (hereinafter 'HV') involves aesthetic, experiential, and emotional benefits resulting in fun, pleasure and excitement (Chitturi et al., 2008; Dhar \& Wertenbroch, 2000). For instance, if a Bluetooth speaker has good sound quality, it makes the user happy because of the sound quality, which means pragmatic value. If the form of the speaker is beautiful, it also makes the user aesthetically-pleasing, which refers to hedonic value.

Although PV has been emphasized as the fundamental purpose of designed products, HV has been also seen as one of the factors affecting the user experience as much as PV (Hassenzahl, 2018; Saariluomaand and Jokinen, 2014; Karapanos et al., 2009). Hassenzahl (2004) claimed that HV is a means to better understand how technology-related functions are experienced. According to Berry et al. (2002), both PV and HV contribute to creating positive user experience with product. A judgment of user experience is made based upon the analysis of PV and HV with a product (Sandström et al., 2008; Prahalad and Ramaswamy, 2000). After all, a judgment whether or not a product is satisfactory is much dependent upon experience derived from both PV and HV (Sweeney and Soutar, 2001; Holbrook and Hirschman, 1982).

While PV and HV of a product influence user experience, the criteria of judging the values are based on user expectations. This means user expectations have to be identified in order to figure out anticipated PV and HV (Chitturi et al., 2008; 2007; Higgins, 2001; Dhar and Wertenbroch, 2000). For instance, users tend to put an emphasis on PV under their functional expectations to be fulfilled (Chitturi et al., 2007; Higgins, 2001), which has an association with efficient and effective usage (Sandström et al., 2008). Likewise, HV is emphasized under their emotional expectations (aesthetic and fun) to be fulfilled for a certain product.

Since technologies are increasingly advanced, product attributes are often pre-determined by technology. In particular, a number of existing functions in products have converted to smart functions (e.g., better home energy management, improved security, healthcare service, etc.). Given the rapid of growth in technology, smart functions are more and more embedded in product for which users do not need to conduct any further work (Parasuraman, 2000). One of the good examples that can explain this phenomenon is smart watch. Smart watch has been developed by integrating smart technologies into an analog watch (Krey et al., 2016). A rich set of smart functions have resulted in an increase of the use of smart watches (Hong et al., 2017), allowing us to check current time as well as to listen to music while workout (Krey et al., 2016). Consequently, it is expected that adoption of smart technologies in product will more and more happen. However, smart technologies have not yet been widely adopted by users despite their availability and the benefits they can offer (Coskun et al., 2017).

As a result, it does not seem easy to keep up with all the technological trends in this increasingly technological world. Interestingly, adopting smart technology in a product is related to user expectations in terms of PV and HV. According to Pamir (2010), people have pragmatic and hedonic expectations from products with adoption of technologies depending on smartness dimensions. According to Candi (2007) functional improvement with smart technology is required to meet users' expectations. In other words, without sufficient consideration about functionality with smart technology, it would be hard to guarantee positive user experiences in the fast-moving trend. In

\footnotetext{
${ }^{1}$ The concept of product in the study refers to product, service or product-service combination.
} 
addition, too many or few functions in a product and service are not necessarily the only cause of dissatisfactory user experience. However, it is certainly a contributory factor to negative user experience (Hassenzahl, 2018). Users are likely to feel satisfaction if user expectation concerning functionality exceeds. If not, there are occasions to evoke high arousal feeling of anger (Chitturi et al., 2007; Roseman, 1991; Smith and Lazarus, 1990). Thus, it is for sure that functional considerations have much to do with user expectation in a product and service. In particular, HV is a means to better understand how technology-related functions are experienced (Hassenzahl, 2004).

Nevertheless, little research has been conducted on product semantic from the perspective of user's expectation according to the adoption of smart technologies. Under the circumstance of increased applications of smart technology in products, latent semantic analysis with regard to PV and HV needs to be examined. Therefore, the study aims to investigate 1) how product semantic (PV and HV) is influenced by the extent to which smartness of technology is applied to a product and 2) what particular functions have to be considered in the context of smart technology-driven design in terms of PV and HV. This study may provide a meaningful approach for designers to resolve how to fulfill user expectations and at the same time increase user satisfaction in the era of smart technology world.

\section{METHOD}

An on-line questionnaire survey was conducted in order to explore how product semantic and user expectations vary in terms of level of technology. For the study, analog watch and smart watch were selected as target products, which are characterized by low and high technology respectively. It was because both types of watch are popularly used and they are ultimately opposed and clearly distinguished in terms of level of technology.

\subsection{Participants}

A total of 104 respondents was recruited to the on-line questionnaire survey through an on-line recruitment agency. The respondents consisted of 52 males and 52 females. Their ages ranged from 21 and 59 years old $(M=38, S D=10.03)$. The respondents consisted of two groups according to their experience with smart watch: one group (26 males and 26 females) had no experience with smart phone but more than one-year experience with analog watch, and the other group had more than one-year hands-on experience with smart watch. Each group of respondents reported that they had been fully aware of and familiar with functions of either analog or smart watch through their hands-on experience.

\subsection{Questionnaire}

A questionnaire was developed to identify product semantic about analog watch and smart watch and also to figure out the expectations of the respondents in terms of function.

In order to measure product semantic of smart and analog watches, 24 pairs of adjectives with fivepoint scales were adopted from previous studies (Batra and Ahtola, 1991; Crowley et al., 1992; Voss et al., 2003) (see Table 1). An open question was used to figure out what functions need to be added for analog watch and removed for smart watch based on the respondents' expectations.

Table 1. The Sematic Differentials (SD) Scales for measuring PV and HV

\begin{tabular}{ccc|ccc}
\hline & PV & & & HV & \\
\hline 'Harmful- & 'Worthless- & 'Impractical- & 'Awful-Nice' & 'Unpleasant- & 'Annoying- \\
Beneficial' & Valuable' & Practical' & 'Sad-Happy' & Pleasant' & Pleasing' \\
'Useless- & 'Ineffective- & 'Unnecessary- & 'Disagreeable- & 'Not fun- & 'Not thrilling- \\
Useful' & Effective' & Necessary' & Agreeable' & Fun' & Thrilling' \\
'Foolish- & 'Unhelpful- & 'Chaotic- & 'Boring- & 'Dull- & 'Unenjoyable- \\
Wise' & Helpful' & Ordered' & Interesting' & Exciting' & Enjoyable' \\
'Not & 'Insane- & & 'Aggravating- & 'Ugly- & 'Not delightful- \\
functional- & Sane' & & Soothing' & Beautiful' & Delightful' \\
Functional' & & & & & \\
\hline
\end{tabular}




\subsection{Procedure}

The respondents were invited to the on-line survey by clicking a link sent in the invitation email. They were instructed to fill out the questionnaire step by step. The questionnaire started with questions asking about their demographic backgrounds such as gender and age. Then, pictograms representing analog and smart watch respectively were provided with the questions about semantic difference (SD). At the end of the question on SD, the open question was asked allowing to give multiple responses. This question inquired about functions they ideally expect from analog and smart watch respectively: for the analog watch group, the question was only about functions they wished to add/remove for analog watch, and for the smart watch group it was only for smart watch. After all the questions were answered, they could move to the next section. The answers given by participants were automatically saved to a database on the Internet.

\subsection{Data analysis}

The data collected from participants were statistically analyzed using SPSS 22. Firstly, ANOVA was used to compare a mean difference of semantic differentials between analog and smart watches. Second, a frequency analysis was conducted to see the difference of expected functions between two watches based on functional categorization shown in Figure 1. The categories were derived from representative functions of existing smart watches such as Apple Watch, Samsung S-watch, and Zetime. According to the categorization, 8 functions such as Notification, Health \& Fitness, Tool, Communication, Controller with IoT, Payment, Lifestyle, and GPS are related to PV while Design and Entertainment correspond to HV.

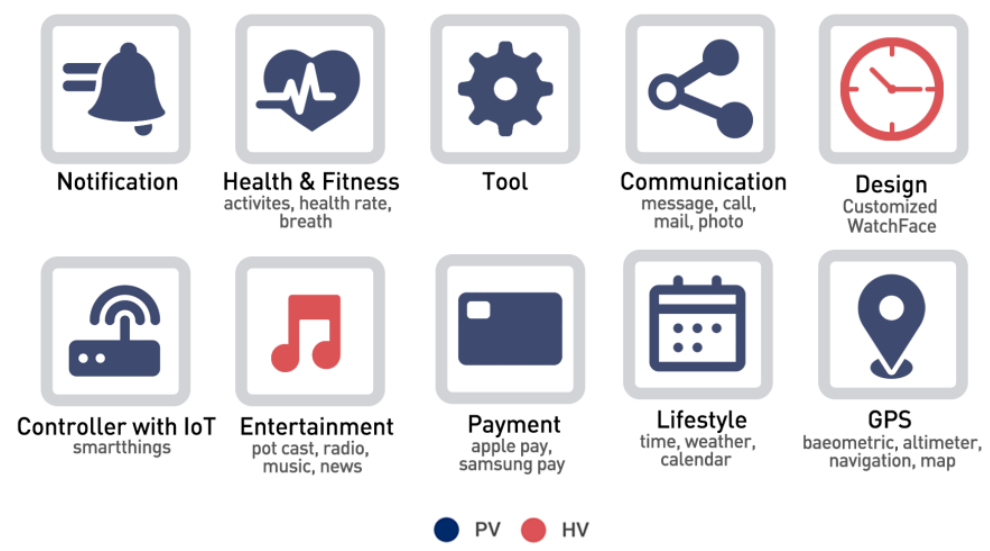

Figure 1. Functional categorization for the analysis of expected functions

\section{RESULTS}

\subsection{Product semantic between analog and smart Watches}

Semantic differentials used in the survey were analyzed to explore how PV and HV vary between analog and smart watches. According to the results of ANOVA analysis, there were statistically significant between means of $\mathrm{PV}(F=4.529, M=4.112, p<.05)$ and $\mathrm{HV}(F=11.591, M=3.832, p<.05)$. This implies that watch is perceived as having more pragmatic than hedonic value regardless of analog and smart watches. Another result is that there is also significant difference between analog $(M$ $P V=3.998, M-H V=3.626)$ and smart watches $(M-P V=4.236, M-H V=4.043)$ in terms of product semantic. A possible implication is that smart watch provides more hedonic experience than analog watch.

In order to see the differences within PV and HV paired adjectives, ANOVA analysis was again conducted (Figure 2). 


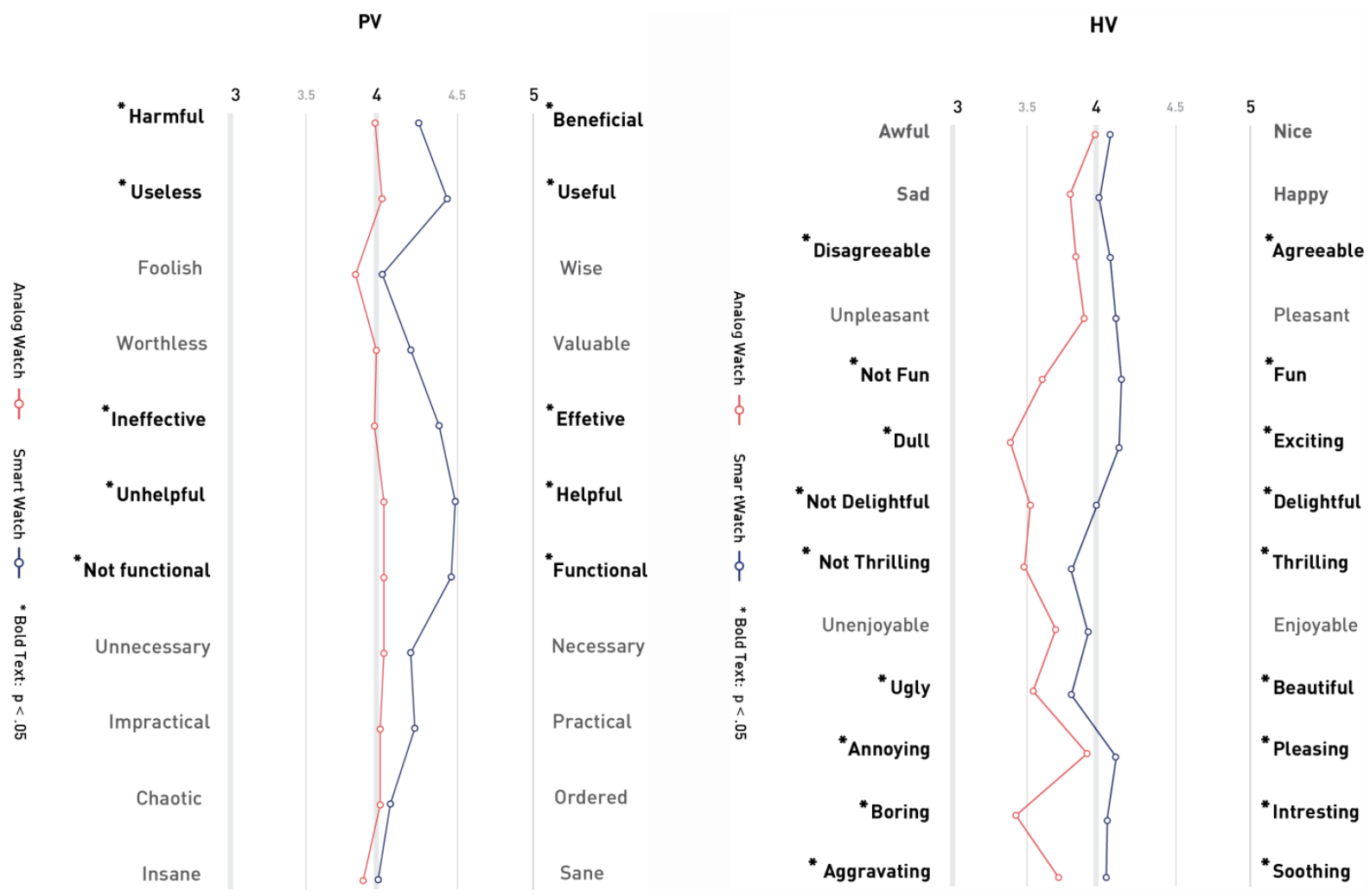

Figure 2. Comparison of $S D$ between analog and smart Watches

In PV, significant differences were found in 'harmful-benefit', 'useless-useful', 'ineffective-effective', 'unhelpful-helpful', and 'not functional-functional' (see details in Table 2). However, there were no significant differences in the other 6 adjective-pairs such as 'foolish-wise', 'worthless-valuable', 'unnecessary-necessary', 'impractical-practical', 'chaotic-ordered', and 'insane-sane'. Regarding HV, there were significant differences in 9 adjective-pairs such as 'disagreeable-agreeable', 'not fun-fun', 'dull-exciting', 'not delightful-delightful', 'not thrilling-thrilling', 'ugly-beautiful', 'annoyingpleasing', 'boring-interesting', and 'aggravating-soothing'. On the other hands, 'awful-nice', 'sadhappy', 'unpleasant-pleasant', and 'unenjoyable-enjoyable' were not statistically significant between analog and smart watches. The results indicate that pragmatic experience such as benefit, useful, effective, helpful, and functional are more appreciated in smart watch than analog watch. In terms of hedonic experience, more agreeable, fun, exciting, delightful, thrilling, beautiful, pleasing, interesting, and soothing were more experienced in smart watch than analog watch. 
Table 2. Results of ANOVA of Sematic Difference (SD) between analog and smart watches

\begin{tabular}{|c|c|c|c|c|c|c|}
\hline Factor & Adjective-Pairs & $\bar{M}$ & $\bar{F}$ & $\bar{P}$ & A-M & S-M \\
\hline \multirow[t]{11}{*}{$\overline{\mathrm{PV}}$} & 'harmful-benefit'* & 4.106 & 4.013 & .048 & 3.981 & 4.240 \\
\hline & 'useless-useful'* & 4.212 & 5.104 & .026 & 4.056 & 4.380 \\
\hline & 'ineffective-effective'* & 4.154 & 7.061 & .009 & 3.981 & 4.340 \\
\hline & 'unhelpful-helpful'* & 4.240 & 5.881 & .017 & 4.074 & 4.420 \\
\hline & 'not functional-functional'* & 4.231 & 4.875 & .029 & 4.074 & 4.400 \\
\hline & 'foolish-wise' & 3.923 & 2.990 & .087 & 3.796 & 4.060 \\
\hline & 'worthless-valuable' & 4.096 & 2.037 & .157 & 4.000 & 4.200 \\
\hline & 'unnecessary-necessary' & 4.135 & 0.782 & .379 & 4.074 & 4.200 \\
\hline & 'impractical-practical' & 4.125 & 1.465 & .229 & 4.037 & 4.220 \\
\hline & 'chaotic-ordered' & 4.067 & 0.208 & .649 & 4.037 & 4.100 \\
\hline & 'insane-sane' & 3.952 & 1.229 & .270 & 3.870 & 4.040 \\
\hline \multirow[t]{13}{*}{$\mathrm{HV}$} & 'disagreeable-agreeable'* & 3.933 & 4.447 & .037 & 3.778 & 4.100 \\
\hline & 'not fun-fun'* & 3.856 & 13.460 & .000 & 3.556 & 4.180 \\
\hline & 'dull-exciting'* & 3.740 & 24.347 & .000 & 3.352 & 4.160 \\
\hline & 'not delightful-delightful'* & 3.731 & 10.551 & .002 & 3.481 & 4.000 \\
\hline & 'not thrilling-thrilling'* & 3.625 & 6.361 & .013 & 3.444 & 3.820 \\
\hline & 'ugly-beautiful'* & 3.654 & 4.312 & $\begin{array}{l}.040 \\
.036\end{array}$ & 3.500 & 3.820 \\
\hline & 'annoying-pleasing'* & 3.990 & 4.502 & .036 & 3.852 & 4.140 \\
\hline & 'boring-interesting'* & 3.721 & 18.461 & .005 & 3.389 & 4.080 \\
\hline & 'aggravating-soothing'* & 3.865 & 8.125 & & 3.667 & 4.080 \\
\hline & 'awful-nice' & 3.990 & 1.403 & .239 & 3.907 & 4.080 \\
\hline & 'sad-happy' & 3.875 & 3.160 & .078 & 3.741 & 4.020 \\
\hline & 'unpleasant-pleasant' & 3.981 & 3.801 & .054 & 3.833 & 4.140 \\
\hline & 'unenjoyable-enjoyable' & 3.788 & 3.689 & .058 & 3.648 & 3.940 \\
\hline
\end{tabular}

A-M: mean of analog watch / S-M: mean of smart watch, ${ }^{*} p<.05$

\subsection{Expected functions and their relation to product semantic}

According to the results, analog watch users added functions because it has only a few functions. However, smart watch users wanted to get rid of functions probably because smart watch has too many functions considering all functions are not used. Figure 4 shows the functions expected for analog watch users and unnecessarily anticipated for smart watch users. For analog watch, Tools $(23.25 \%)$ were most frequently mentioned, which include mirror, flash, and so on. It was followed by GPS (18.60\%) and Notification (16.28\%). And Health \& Fitness (11.63\%), Design (11.63\%), Lifestyle (6.98\%), Communication (6.98\%), and Entertainment $(4.65 \%)$ were reported. On the other hands, Notification $(24.25 \%)$ was most frequently mentioned as unnecessary function among smart watch users. This was followed by Entertainment (12.12\%), Communication (12.12\%), Design (9.09\%), Health \& Fitness (9.09\%) and Lifestyle (9.09). GPS (6.06\%) and Payment (6.06\%) were least reported as unnecessary function for smart watch. Interestingly, Controller with IoT $(12.12 \%)$ was the only function that smart watch users expected to add.

In terms of PV and HV, the wanted functions for analog watch and the unwanted functions for smart watch were analyzed. Having described in Figure 1, 8 functions such as Notification, Health \& Fitness, Tools, Communication, Controller with IoT, Payment, Lifestyle, and GPS are related to PV. However, Design and Entertainment were regarded as functions related to HV. For analog watch, functions for hedonic experience only took approximately $16 \%$ while functions related to pragmatic experience took up most of expected functions. However, smart watch users expected to reduce a number of functions related to pragmatic experience. The demand of reducing functions related to hedonic experience was not significant (approximately $21 \%$ ). 


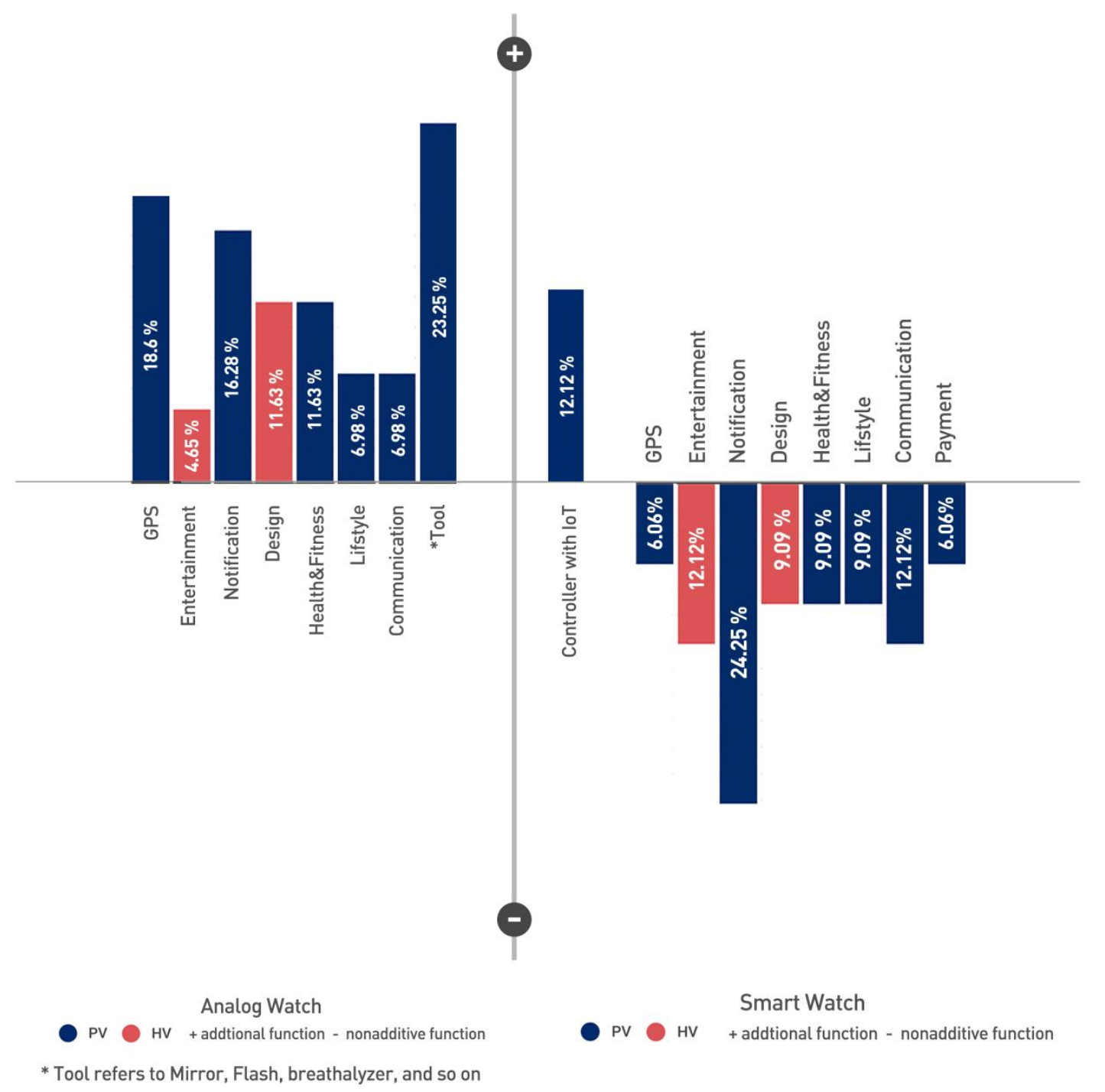

Figure 3. Percentages of expected functions for analog watch (left) and unnecessary functions for smart watch (right)

\section{Discussion}

\subsection{Product semantic according to level of technology}

In the study, it was investigated how semantic differences between analog and smart watches are influenced by the level of technology. It was in a line with previous studies (Chitturi et al., 2008; Higgins 2001; Dhar and Wertenbroch, 2000) that respondents have a significant difference on PV and HV between two different groups. The results indicate that both PV and HV were more experienced in smart watch than in analog watch. This implies that redesigning existing products with smart technology may increase both pragmatic and hedonic experience at the same time. The reason is probably because $\mathrm{HV}$ is derived from functions that better reflect the kind of users' PV (Sandström et al., 2008; Berry et al., 2002). From this perspective, a combination of PV and HV appears in user expectation.

According to the results of semantic differentials, smart watch is perceived as more effective and useful than analog watch. This means users are much satisfied with smart functionality of their smart watch. It also seems that the functional experience could deliver fun and exciting emotion as well. This is in line with Hassenzahl's study (2004) in which he argued that HV is a means to better understand how technology-related functions are experienced. Therefore, emotional experience needs to be considered when functions with smart technology are intended by design practitioners in order to increase user satisfaction with smart products and services. 


\subsection{Expected functions for products with smart technology}

According to the results, most of expected functions were related to PV in analog watch while the same percentage of unwanted functions to the value in smart watch as well. This implies that adding various functions with smart technology to a product is not always an effective approach, which is in line with Hassenzahl's study (2018). However, it seems adding more smart functions to analog watch would increase user satisfaction. Unlike PV, the ratio of functions related to HV were low in opposite direction for both watches. For analog watch, design and entertainment were mentioned as wished function while they were something unwanted for smart watch. This implies that a moderate number of functions related to hedonic experience may guarantee better user experience for analog watch. But pragmatic value seems more appreciated than hedonic value in smart watch. Probably, paying more attention to functions related to pragmatic value may better meet the users of smart watch.

Regarding type of functions, wanted functions for analog watch were widely distributed from GPS and Notification to Health \& Fitness and Communication, but unwanted ones for smart watch were mainly on Notification and Communication. The excessive notification and communication from applications of smart watch seems bothersome. Therefore, it seems necessary to consider a moderate degree of notification experience in designing products with smart technology. In addition, it is interesting that the analog watch group wanted particular functions such as a mirror, flash, and sound effect to check a time, which are not expected in watch and have no direct relevance from the fundamental role of a watch. From this, we could assume that people expect not only the main function of watch but also instrumental functions from analog watch It might mean that these auxiliary functions to help user live life might be more necessary than other smart functions in digitalization for users who want to keep their analog sensibility. On the other hand, analog products armed with smart technologies may promote interaction with other products or services and per se contribute to an increase of user experience. The smart technology, for example, expands service quality dimension, promotes collaboration with other products, supports sustainable design, and enriches performance. Therefore, it would be a good strategy for design practitioners to adopt smart technologies to analog products.

\section{CONCLUSIONS}

As smart technologies are getting increasingly popular in product and service design, companies have adopted the technologies to differentiate their products and services and even compete other competitors in the market. The key to this strategy is to meet user expectations for the smartness and increase the demand for more digital-based products. In such context, the study investigated how product semantic based on user experience is influenced by the level of technology and what particular functions have to be taken into account in terms of the product semantic in the context of smart technology-driven design. Overall findings indicate that applying smart technology to product and service could increase the level of both pragmatic and hedonic experience compared to the traditional products and services. However, a careful consideration has to be taken in making functions smarter because a number of smart functions do not necessarily guarantee to meet user's expectations. Although the study could provide design practitioners with design recommendations in developing products and services with smart technologies, there have some limitations. It would be difficult to generalize the findings considering the study focused only on watch as a case of products. Furthermore, individuals' prior experience with analog watch might have influenced the results although we tried to control this by using pictograms of analog watch and smart watch. By adopting research method as survey, we are also still unknown why particular functions were wanted and unwanted. Therefore, further studies should consider the influence of prior experience and different types of products with another research methods such as in-depth interview and observation.

\section{ACKNOWLEDGEMENT}

This work was supported by the 'Promotion of Special Design-Technology Convergence Graduate School' of the Korea Institute of Design Promotion with a grant from the Ministry of the Trade, Industry \& Energy, Republic of Korea (N0001436). 


\section{REFERENCES}

Batra, R. and Ahtola, O.T. (1991), "Measuring the hedonic and utilitarian sources of consumer attitudes", Marketing Letters, Vol. 2 No. 2, pp. 159-170.

Berry, L., Lewis P, L., and H, C. and Haeckel, S. (2002), "Managing the Total Customer Experience", MIT Sloan Management Review, Vol. 16 No. 1, pp. 1-15.

Candi, M. (2007), "The role of design in the development of technology-based services", Design Studies, Vol. 28 No. 6, pp. 559-583.

Chitturi, R., Raghunathan, R. and Mahajan, V. (2008), "DELIGHT BY DESIGN: The Role of Hedonic Versus Utilitarian Benefits", Journal of Marketing Article, pp. 1-49.

Chitturi, R., Raghunathan, R. and Mahajan, V. (2007), "Form Versus Function:How the Intensities of Specific Emotions Evoked in Functional Versus Hedonic Trade-Offs Mediate Product Preferences", Journal of Marketing Research, Vol. 44 No. 4, pp. 702-714.

Crowley, A.E., Spangenberg, E.R. and Hughes, K.R. (1992), "Measuring the hedonic and utilitarian dimensions of attitudes toward product categories", Marketing Letters, Vol. 3 No. 3, pp. 239-249.

Coskun, A., Kaner, G. and Bostan, I. (2017), "Is smart home a necessity or a fantasy for the mainstream user? A study on users' expectations of smart household appliances”, International Journal of Design, Vol. 12 No. 1, pp. 7-20.

Dhar, R. and Wertenbroch, K. (2000), "Consumer Choice Between Hedonic and Utilitarian Goods", Journal of Marketing Research, Vol. 37 No. 1, pp. 60-71.

Hassenzahl, M. (2004), “The Interplay of Beauty, Goodness, and Usability in Interactive Products”, Human Computer Interaction, Vol. 19, pp. 319-349.

Hassenzahl, M. (2018), "The thing and I: understanding the relationship between user and product", Funology, Vol. 2, Springer International Publishing, pp. 301-313.

Higgins, E.T. (2001), Promotion and Prevention Experiences: Relating Emotions to Nonemotional Motivational States., In J. P. Forgas (Ed.), Handbook of Affect and Social Cognition.

Holbrook, M.B. and Hirschman, E.C. (1982), “The experiential aspects of consumption: Consumer fantasies, feelings, and fun", Journal of Consumer Research, Vol. 9 No. 2, pp. 132-140.

Hong, J.C., Lin, P.H. and Hsieh, P.C. (2017), "The effect of consumer innovativeness on perceived value and continuance intention to use smartwatch", Computers in Human Behavior, Elsevier Ltd, Vol. 67, pp. 264-272.

Karapanos, E., Zimmerman, J., Forlizzi, J. and Martens, J. (2009), “User experience over time”, CHI, pp. 729-738.

Krey, N., Rauschnabel, P., Chuah, S., Nguyen, B., Hein, D., Rossmann, A. and Lade, S. (2016), "Smartwatches: Accessory or Tool? The Driving Force of Visibility and Usefulness", Mensch Und Computer, No. September 2016, pp. 1-12.

Norman, D. (2004). Emotional Design: Why We Love (or Hate) Everyday Things, Basic Civitas Books.

Pamir, N. (2010), Smart products: technological applications vs user expectations, Master thesis, Middle East Technical University.

Parasuraman, R. (2000), "Designing automation for human use: Empirical studies and quantitative models", Ergonomics, Vol. 43 No. 7, pp. 931-951.

Roseman, I.J. (1991), “Appraisal determinants of discrete emotions”, Cognition and Emotion, Vol. 5 No. 3 , pp. 161-200.

Saariluomaand, P. and Jokinen, J.P.P. (2014), "Emotional Dimensions of User Experience: A User Psychological Analysis”, International Journal of Human-Computer Interaction, Vol. 30 No. 4, pp. 303-320.

Sandström, S., Edvardsson, B., Kristensson, P. and Magnusson, P. (2008), "Value in use through service experience”, Managing Service Quality: An International Journal, Vol. 18 No. 2, pp. 112-126.

Smith, C. A., \& Lazarus, R.S. (1990). Emotion and Adaptation., Handbook of Personality: Theory and Research, Vol. 21, Available at:https://doi.org/10.2307/2075902.

Sweeney, J. and Soutar, G. (2001), "Consumer Perceived value: The developmetn of a multiple item scale", Journal of Retailing, Vol. 77, pp. 203-220.

Voss, K., Spangenberg, E. and Grohmann, B. (2003), "Measuring the Hedonic and Utilitarian Dimensions of Consumer Attitude", Journal of Marketing Research, Vol. XL No. August 2003, pp. 159-170. 
